\title{
Nano copper and cobalt ferrites as heterogeneous catalysts for the one-pot synthesis of 2,4,5-tri substituted imidazoles
}

\author{
PAUL DOUGLAS SANASI*, D SANTHIPRIYA, Y RAMESH, M RAVI KUMAR, B SWATHI \\ and K JAYA RAO \\ Department of Engineering Chemistry, A.U. College of Engineering (A), Andhra University, \\ Visakhapatnam 530 003, Andhra Pradesh, India \\ e-mail: pauldouglas12@gmail.com
}

MS received 18 March 2014; revised 26 May 2014; accepted 04 June 2014

\begin{abstract}
A simple one-pot synthesis has been developed for the synthesis of 2,4,5-trisubstituted imidazoles using magnetic recyclable spinel nano copper and cobalt ferrites by the condensation of benzil, aromatic aldehyde and ammonium acetate in ethanol as solvent. The reaction, with these catalysts was carried out under mild reaction conditions with very good yields of substituted imidazoles. These catalysts can be recycled very easily and reused, which makes this methodology environmentally benign.
\end{abstract}

Keywords. Heterogeneous catalysts; nano copper and cobalt ferrites; one-pot synthesis; 2,4,5-tri substituted imidazoles.

\section{Introduction}

Multi-component reactions carried out in one-pot process are of interest as they form a single product with high yields. ${ }^{1,2}$ These reactions are convenient and powerful tools for the preparation of a few biologically and pharmaceutically active organic compounds. Many biologically active natural products were found to contain substituted imidazole structures. Tri aryl imidazole is the main structural unit in some widely used drugs such as ketoconazole, ${ }^{3}$ proton pump inhibitors omeprazole, ${ }^{4}$ cimetidine, ${ }^{5}$ clotrimazole ${ }^{6}$ and metronidazole, ${ }^{7}$ potential inhibitor of $\mathrm{P}^{38}$ mapkinase, ${ }^{8}$ therapeutic agents ${ }^{9}$ and anti HIV-I protease. ${ }^{10}$

Numerous methods have been developed for the synthesis of substituted imidazoles. 2,4,5-trisubstituted imidazoles can be prepared by a three-component cyclo condensation in the presence of acetic acid, ${ }^{11}$ silica supported sulphuric acid, ${ }^{12} \mathrm{InCl}_{3} \cdot 3 \mathrm{H}_{2} \mathrm{O},{ }^{13}$ ceric ammonium nitrate, ${ }^{14}$ iodine,${ }^{15}$ trichloroisocyanuric acid (TCCA), ${ }^{16}$ $\mathrm{NiCl}_{2} \cdot 6 \mathrm{H}_{2} \mathrm{O} / \mathrm{Al}_{2} \mathrm{O}_{3},{ }^{17}$ ionic liquids, ${ }^{18}$ zeoliteHY/silica gel ${ }^{19}$ and $\mathrm{ZrCl}_{4}{ }^{20}$ under reflux conditions. Although these methods have a lot of potential, the reactions suffer from low yields, longer reaction times, use of expensive reagents, associated with a mixture of products and lack of generalization. Thus, they were not appropriate for synthesis of structurally diverse imidazoles. Development of clean and high yielding and environmentally benign approaches is still desirable and much in demand.

\footnotetext{
*For correspondence
}

In continuation to our efforts to explore the catalytic activity of magnetically separable substituted nanoferrites for various organic transformations, it is observed that the efficacy of copper and cobalt nanoferrite catalysts for the synthesis of trisubstituted imidazoles has not been explored before. Hence, the influence of nanoferrite catalyst in the one-pot synthesis of 2,4,5,-trisubstitued imidazoles by cyclocondensation of benzil, benzaldehyde and ammonium acetate (scheme 1) has been attempted. Previously, copper and cobalt nanoferrites were synthesized and used for various organic transformations. ${ }^{21-27}$ Now a one-pot synthesis of 2,4,5,-trisubstituedimidazoles has been carried out using cobalt and copper substituted nanoferrites and the results are reported.

\section{Experimental}

\subsection{Catalyst preparation}

Solvents and reagents were of AR grade acquired from the commercial sources and used without purification. Magnetic spinel nanoferrite catalysts with composition $\mathrm{MFe}_{2} \mathrm{O}_{4}[\mathrm{M}=\mathrm{Cu} / \mathrm{Co}]$ were chosen for this study. For the preparation of catalysts, aqueous solutions of stoichiometric amounts of copper and cobalt nitrates along with ferric citrate were reacted with citric acid in 1:1 molar ratio. $\mathrm{pH}$ of the solution was increased to 7 by addition of ammonia to complete the reaction and ethane diol was added. The solution was 


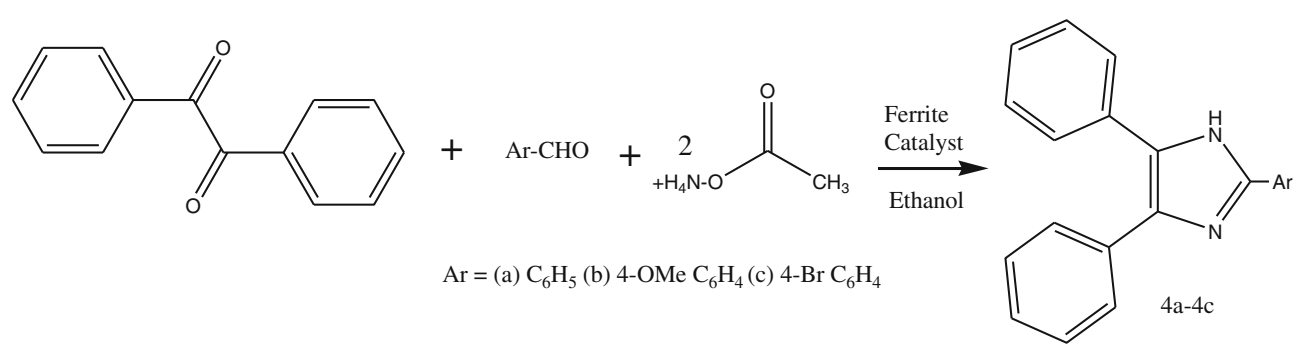

Scheme 1. One-pot synthesis of 2,4,5,-trisubstituted imidazoles.

evaporated very slowly over a period of ten to twelve hours to dryness. Viscosity and colour changed as the solution turned into a puffy and porous dry gel. As soon as the solvent removal completed, dried precursor underwent a self-ignition reaction to form a very fine powder known as as-synthesized powder. The assynthesized powders, thus obtained were calcined in a muffle furnace at $500^{\circ} \mathrm{C}$ for $2 \mathrm{~h}$ to remove the residual carbon and furnace cooled.

\subsection{Characterization}

For the characterization of the calcined as-synthesized nanoferrites, the XRD spectra were recorded on PANalytical-Xpertpro diffractometer and the average crystallite size was determined from the corresponding XRD data. The microstructural morphology was studied with a scanning electron microscope (SEM) model JEOL-JSM 6610 LV. FTIR spectra were recorded on BRUKER ALPHA FT-IR with Opus 6.1 version. Magnetization $\mathrm{M}(\mathrm{H})$ measurements were made using a commercial vibrating sample magnetometer (VSM) model BHV-50 of Riken Denshi Co. Ltd. Japan. Specific surface area (SBET) of samples was determined by BET surface area analyzer (Nova 2000 series, Quantachrome Instruments, UK). Melting points were determined on a capillary melting point apparatus and are uncorrected. ${ }^{1} \mathrm{HNMR}$ and ${ }^{13} \mathrm{CNMR}$ spectral data were recorded on the Bruker-Avance 300-MHz spectrometer in DMSO-d6. The chemical shift values were reported on the $\delta$ scale in parts per million (ppm), downfield from tetramethylsilane (TMS) as an internal standard. The mass spectrum was recorded using a Perkin-Elmer PE SCIEX-API 2000, equipped with ESI source used online with a HPLC system after the ultraviolet (UV) detector.

\subsection{Characterization of nanoferrites}

2.3a X-ray diffraction (XRD) analysis: Figures S1 and S2 (see supplementary information) show typical
XRD pattern for copper and cobalt nanoferrite samples respectively, which were sintered at $500^{\circ} \mathrm{C}$. The pattern shows all the characteristic peaks of a spinal structure and confirms the phase formation indicating the absence of other impurity phases. The XRD parameters of various peaks were compared with the standard data of the cubic copper ferrites (JCPDS \# 77-10) and found to be in cubic phase and cobalt ferrites nos. (JCPDS3-864 and 22-1086). The particle size and other characteristics of the copper and cobalt ferrite nano particles obtained from the XRD pattern using Scherer's formula ${ }^{28-30}$ was found to be 29 and $27 \mathrm{~nm}$ respectively and reported in table 1 . The peaks can be indexed to (111), (220), (311), (222), (400), (422), (511) and (440) planes of a cubic unit cell.

2.3b Infrared Spectroscopy: In order to confirm the formation of the spinel phase and to understand the nature of the residual carbon in the samples, the FTIR spectra of the as-synthesized powders and thermally treated powder were recorded and shown in figures S3 and S4. The as-synthesized sample shows characteristic absorptions of ferrite phase with a strong absorption around $600 \mathrm{~cm}^{-1}$. Waldron studied the vibrational spectra of ferrites and attributed the sharp absorption band around $580 \mathrm{~cm}^{-1}$ to the intrinsic vibrations of the tetrahedral groups and the other band of the octahedral groups. There are two weak and broad absorptions around 1040, 1400, 1600, $3400 \mathrm{~cm}^{-1}$ corresponding to the presence of small amount of residual carbon in the samples. These absorptions in the present case are very weak which indicate that the residual carbon has mostly burnt away during the sintering process.

2.3c Morphological and elemental analysis (SEM \& $E D X)$ : Figures $\mathrm{S} 5$ and $\mathrm{S} 6$ show the typical SEM image of the nano copper and cobalt nanoferrites sintered at $500^{\circ} \mathrm{C}$. The crystallite size calculated from XRD is in the range of below $30 \mathrm{~nm}$ which is in agreement with the SEM image. The structural composition and crystallinity of the cobalt ferrite nano particles was further 
Table 1. Particle size and other characteristics of copper and cobalt ferrites.

\begin{tabular}{lccccccc}
\hline S No & Sample & Lattice Parameter & Density (\%) & FWHM & Porosity (\%) & Grain size (D) $(\mu \mathrm{m})$ & Particle Size \\
\hline 1 & $\mathrm{CuFe}_{2} \mathrm{O}_{4}$ & 8.387 & 92.5 & 0.281 & 7.4 & 1.62 & 29 \\
2 & $\mathrm{CoFe}_{2} \mathrm{O}_{4}$ & 8.389 & 91.9 & 0.272 & 7.3 & 1.58 & 27 \\
\hline
\end{tabular}

examined by using SEM and TEM. The iron and copper or cobalt ratio in the nano crystals as determined by EDX analysis was very much close to the atomic ratio in the formula $\mathrm{CuFe} 2 \mathrm{O} 4$ and $\mathrm{CoFe} 2 \mathrm{O} 4$.

2.3d BET surface area analysis: The BET surface area of the $\mathrm{CuFe}_{2} \mathrm{O}_{4}$ and $\mathrm{CoFe}_{2} \mathrm{O}_{4}$ are found to be 127 and $135 \mathrm{~m}^{2} / \mathrm{g}$ respectively. The difference in the surface area of the samples is attributed to the atomic sizes of copper and cobalt. Further, copper ferrite shows decrease in surface area during calcination at $500^{\circ} \mathrm{C}$. This may be due to the completion of dehydration associated with the completion of crystallization and growth of crystallite size by sintering.

\subsection{One pot synthesis of 2,4,5, trisubstituted imidazoles}

The one-pot synthesis of substituted imadazoles was carried out in a $50 \mathrm{~mL}$ round bottomed flask equipped with a reflux condenser in an oil bath with temperature control and refluxed. About $500 \mathrm{mg}$ of the catalyst was taken and activated at $500^{\circ} \mathrm{C}$ for $2 \mathrm{~h}$ and cooled to room temperature before the experiment. $10 \mathrm{mmol}$ each of benzil, aromatic aldehyde and $20 \mathrm{mmol}$ of ammonium acetate were mixed together along with the catalyst and $10 \mathrm{~mL}$ of ethanol as solvent and refluxed. The completion of the reaction was checked with TLC (nhexane: ethyl acetate 4:1) and the products were isolated by removing the catalyst magnetically from the reaction mixture. All the products are known in the literature and were identified by IR, ${ }^{1} \mathrm{HNMR},{ }^{13} \mathrm{CNMR}$ and mass spectra of representative compounds and compared.

\subsection{Spectral data of substituted imidazole derivatives (figures $S 7$ and S15)}

2.5a 2,4,5,triphenyl 1-H-Imidazole (4a): M.p. 273-275 ${ }^{\circ}$; ${ }^{1} \mathrm{HNMR}$ (Bruker) $\left(\mathrm{CDCl}_{3} / \mathrm{DMSO}-d_{6}\right)$ $\delta=7.97-7.34(\mathrm{~m}, 15 \mathrm{H}), 9.31(\mathrm{brs}, \mathrm{N}-\mathrm{H}),{ }^{13} \mathrm{CNMR}$ $\left(\mathrm{CDCl}_{3} / \mathrm{DMSO}-d_{6}\right) ; 122.5,127.0,128.7,129.2,136.4$ ppm; FTIR (KBr, cm $\left.{ }^{-1}\right): 3450(\mathrm{~N}-\mathrm{H}), 3062(\mathrm{C}-\mathrm{H}), 1658$ $(\mathrm{C}=\mathrm{C}), 1578(\mathrm{C}=\mathrm{N}), \operatorname{NCMS}(\mathrm{m} / \mathrm{z}) ; 297\left(\mathrm{M}^{+}+1\right)$ 2.5b 2-(4-methoxy phenyl)-4,5, diphenyl-1-H Imidazole (4b): M.p. 222-224 ${ }^{\circ} \mathrm{c}$; ${ }^{1} \mathrm{HNMR}$ (Bruker) $\left(\mathrm{CDCl}_{3} / \mathrm{DMSO}-d_{6}\right) \delta=3.85(\mathrm{~S}, 3 \mathrm{H}), 6.97-6.95(\mathrm{~d}, \mathrm{~J}$ $=8.8 \mathrm{~Hz}, 2 \mathrm{H}), 7.54-7.25(\mathrm{~m}, 10 \mathrm{H}), 7.84-7.82(\mathrm{~d}, \mathrm{~J}=$ $8.8 \mathrm{~Hz}, 2 \mathrm{H}),{ }^{13} \mathrm{CNMR}\left(\mathrm{CDCl}_{3} / \mathrm{DMSO}-d_{6}\right), 55.7,113.4$, 122.6, 126.3, 126.6, 128.0, 128.3, 133.4, 145.7, 159.6 ppm; FTIR $\left(\mathrm{KBr}, \mathrm{cm}^{-1}\right) ; 3450(\mathrm{~N}-\mathrm{H}), 1612(\mathrm{C}=\mathrm{C})$, 1579(C=N), 1385(C-O), NCMS $(\mathrm{m} / \mathrm{z}) 327\left(\mathrm{M}^{+}+1\right)$

2.5c 2-(4-Bromo phenyl)-4,5, diphenyl-1-H Imidazole (4c): M.p. $260-262^{\circ} \mathrm{C} ;{ }^{1} \mathrm{HNMR}$ (Bruker) $\left(\mathrm{CDCl}_{3} / \mathrm{DMSO}-d_{6}\right): \delta=7.76-7.05(\mathrm{~m}, 10 \mathrm{H}), 7.97-$ $7.92(\mathrm{~d}, \mathrm{~J}=8.0 \mathrm{~Hz}, 2 \mathrm{H}), 6.71-6.67(\mathrm{~d}, \mathrm{~J}=8.6 \mathrm{~Hz}, 2 \mathrm{H})$; ${ }^{13} \mathrm{CNMR}\left(\mathrm{CDCl}_{3} / \mathrm{DMSO} \mathrm{d}_{6}\right) ; \delta=122.2,125.4,126.5$, $128.8,129.9,132.8,144.3 \mathrm{ppm}$; FTIR $\left(\mathrm{KBr}, \mathrm{cm}^{-1}\right)$; 3432(N-H), $1600(\mathrm{C}=\mathrm{C}), \quad 1482(\mathrm{C}=\mathrm{N}), \quad 729(\mathrm{C}-\mathrm{Br})$, NCMS (m/z) $367\left(\mathrm{M}^{+}+1\right)$

\section{Results and Discussion}

\subsection{Catalytic Study}

It can be understood from the similar studies reported in the literature, ${ }^{31}$ the plausible mechanism with the copper and cobalt catalyst in the reaction may be shown in scheme 2. The Aldehyde and 1,2-diketone are first activated by ferrite nanoparticles $\left(\mathrm{Fe}^{3+}\right)$ to afford $\mathrm{A}$ and $\mathrm{B}$ respectively. The imine intermediate (A), condenses further with the carbonyl carbon or 1,2 diketone imine (B) and formation of carbocation (C) followed by attack of imine nitrogen to positive centre and dehydration to afford the imo-imidazole (D), which rearranges via ${ }^{1,5}$ sigmatropic shift followed by deprotonation gives the imidazole.

3.1a Comparison of effect of the present catalysts with other catalysts on synthesis of 2,4,5, tri-substituted imidazoles: It is observed from table 2, that copper and cobalt ferrites have shown similar effective yields when compared to iodine and TCCA with minimum reaction times, which is a significant contribution in this method.

3.1b Effect of solvent on synthesis of 2,4,5, trisubstituted imidazoles: Investigation of reaction medium 

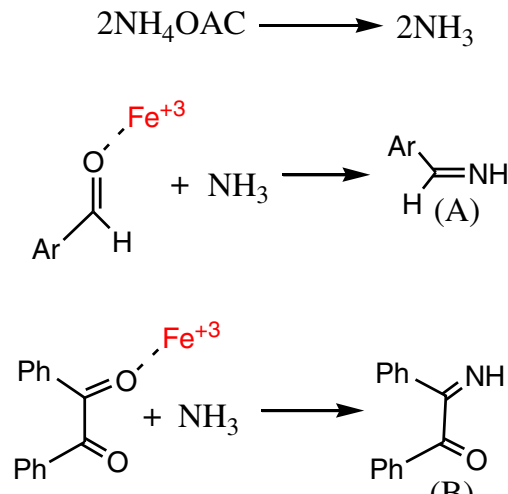

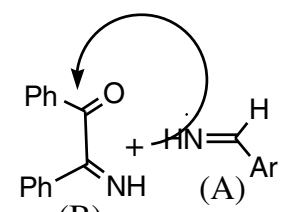

(B)

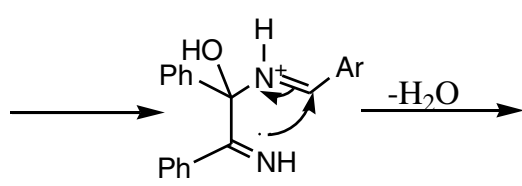

(C)

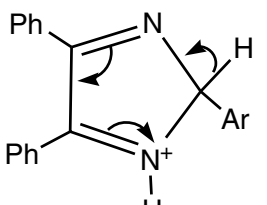

(D) $\mathrm{H}$ $-\mathrm{H}^{+}$<smiles>[Al]c1nc(-c2ccccc2)c(-c2ccccc2)[nH]1</smiles>

Scheme 2. Plausible mechanism for the formation of 2,4,5 tri-substituted imidazoles

for the process revealed that solvents played an important role in the reaction under investigation. The results are summarized in table 3 . It was found that polar solvents such as acetic acid, $\mathrm{CH}_{3} \mathrm{CN}$, and $\mathrm{C}_{2} \mathrm{H}_{5} \mathrm{OH}$ were much better than non-polar solvents. Trace amounts of yield observed when $\mathrm{H}_{2} \mathrm{O}$ was used as solvent, presumably due to the aggregation of the hydrophobic catalyst. Although acetic acid was effective, low yield was obtained when the catalyst was reused. We therefore selected ethanol as solvent.

3.1c Effect of temperature on synthesis of 2,4,5trisubstituted imidazoles: The reaction temperature has a great influence on the model reaction. The reactions were carried out in ethanol at different temperatures ranging from 30 to $70^{\circ} \mathrm{C}$. The results are

Table 2. Comparative catalytic activity of copper and cobalt ferrites with other catalysts.

\begin{tabular}{lccccc}
\hline Sl. No. & Catalyst & $\mathrm{Ar}$ & Time (min) & Temp $\left({ }^{\circ} \mathrm{C}\right)$ & Yield (\%) \\
\hline 1 & Iodine $^{15}$ & $\mathrm{Ph}$ & 15 & 75 & 99 \\
2 & $\mathrm{TCCA}^{16}$ & $\mathrm{Ph}$ & $12 \mathrm{hrs}$ & 85 & 90 \\
3 & $\mathrm{CuFe}_{2} \mathrm{O}_{4}$ & $\mathrm{Ph}$ & 10 & 70 & 94 \\
4 & $\mathrm{CoFe}_{2} \mathrm{O}_{4}$ & $\mathrm{Ph}$ & 10 & 70 & $98(4 \mathrm{a})$ \\
5 & $\mathrm{Iodine}^{15}$ & $4-\mathrm{OMe} \mathrm{C} \mathrm{H}_{4}$ & 25 & 75 & 99 \\
6 & $\mathrm{TCCA}^{16}$ & $4-\mathrm{OMe} \mathrm{C}_{6} \mathrm{H}_{4}$ & $12 \mathrm{hrs}$ & 85 & 89 \\
7 & $\mathrm{CuFe}_{2} \mathrm{O}_{4}$ & $4-\mathrm{OMe} \mathrm{C}_{6} \mathrm{H}_{4}$ & 13 & 70 & 96 \\
8 & $\mathrm{CoFe}_{2} \mathrm{O}_{4}$ & $4-\mathrm{OMe} \mathrm{C}_{6} \mathrm{H}_{4}$ & 10 & 70 & $96(4 \mathrm{~b})$ \\
9 & $\mathrm{Iodine}^{15}$ & $4-\mathrm{Br} \mathrm{C}_{6} \mathrm{H}_{4}$ & - & - & - \\
10 & $\mathrm{TCCA}^{16}$ & $4-\mathrm{Br} \mathrm{C}_{6} \mathrm{H}_{4}$ & $12 \mathrm{hrs}$ & 85 & 90 \\
11 & $\mathrm{CuFe}_{2} \mathrm{O}_{4}$ & $4-\mathrm{Br} \mathrm{C}_{6} \mathrm{H}_{4}$ & 20 & 75 & 92 \\
12 & $\mathrm{CoFe}_{2} \mathrm{O}_{4}$ & $4-\mathrm{Br} \mathrm{C}_{6} \mathrm{H}_{4}$ & 15 & 75 & $94(4 \mathrm{c})$ \\
\hline
\end{tabular}


Table 3. Effect of solvent.

\begin{tabular}{lccccc}
\hline Sl. No. & Catalyst & $\mathrm{Ar}$ & Solvent & Time $(\min )$ & Yield $(\%)^{\mathrm{a}}$ \\
\hline 1 & $\mathrm{CoFe}_{2} \mathrm{O}_{4}$ & $\mathrm{Ph}$ & $\mathrm{H}_{2} \mathrm{O}$ & 60 & trace \\
2 & $\mathrm{CoFe}_{2} \mathrm{O}_{4}$ & $\mathrm{Ph}$ & $\mathrm{CH}_{2} \mathrm{Cl}$ & 60 & 35 \\
3 & $\mathrm{CoFe}_{2} \mathrm{O}_{4}$ & $\mathrm{Ph}$ & $\mathrm{CH}_{3} \mathrm{CN}$ & 45 & 55 \\
4 & $\mathrm{CoFe}_{2} \mathrm{O}_{4}$ & $\mathrm{Ph}$ & $\mathrm{CH}_{3} \mathrm{COOH}$ & 25 & $86,57^{\mathrm{b}}$ \\
5 & $\mathrm{CoFe}_{2} \mathrm{O}_{4}$ & $\mathrm{Ph}$ & $\mathrm{C}_{2} \mathrm{H}_{5} \mathrm{OH}$ & 10 & 98 \\
\hline
\end{tabular}

All reactions were carried out under reflux conditions with $500 \mathrm{mg}$ of catalyst.

${ }^{\mathrm{a}}$ Isolated yields ${ }^{\mathrm{b}}$ Catalyst was reused

Table 4. Effect of temperature.

\begin{tabular}{|c|c|c|c|c|}
\hline \multicolumn{5}{|c|}{ S.No. Catalyst A } \\
\hline 1 & $\mathrm{CoFe}_{2} \mathrm{O}_{4} \mathrm{Ph}$ & R.T. & 300 & 20 \\
\hline 2 & $\mathrm{CoFe}_{2} \mathrm{O}_{4} \mathrm{Ph}$ & 45 & 120 & 45 \\
\hline 3 & $\mathrm{CoFe}_{2} \mathrm{O}_{4} \mathrm{Ph}$ & 60 & 35 & 75 \\
\hline 4 & $\mathrm{CoFe}_{2} \mathrm{O}_{4} \mathrm{Ph}$ & 70 & 10 & 98 \\
\hline
\end{tabular}

presented in table 4 . It is clear that at lower temperatures, even if the times were prolonged to $8 \mathrm{~h}$, only low yields were observed. Consequently, we chose $70^{\circ} \mathrm{C}$ as the optimal temperature for our reaction.

\subsection{Recycling of the catalyst}

Catalyst reusability is of major concern in heterogeneous catalysis. The recovery and reusability of the catalyst was investigated in this reaction with benzaldehyde (4a). Catalyst recycling was achieved by fixing the catalyst magnetically at the bottom of the flask with a strong magnet, after which the solution was taken off with a pipette, the solid washed twice with dichloromethane (DCM) and the fresh substrate dissolved in the same solvent was introduced into the flask, allowing the reaction to proceed for the next run. The catalyst was consecutively reused five times without any noticeable loss of its catalytic activity. These catalysts are highly magnetic and their saturation magnetization values are found to be 32.45 and $35.56 \mathrm{emu} / \mathrm{g}$, which are much higher than other reported magnetic catalysts. Therefore, they could be easily and almost completely separated by an external magnet which is of a great advantage for a heterogeneous catalyst.

\section{Conclusion}

An efficient method has been developed for the synthesis of 2,4,5-tri aryl imidazoles using copper and cobalt nanoferrites. This method offers several advantages including high yield, short reaction time, ease of separation and recyclability of the magnetic catalyst.

\section{Supplementary Information}

Supplementary information contains XRD, FTIR and SEM images of copper and cobalt ferrites (S1-S6) and FTIR, Mass and 1HNMR spectra of substituted imidazoles (S7-S15). For details, see www.ias.ac.in/chemsci.

\section{Acknowledgements}

The authors wish to thank the University Grants Commission (UGC) for all the facilities received through the major research project no. F. 41-371/2012 (SR) to Paul Douglas Sanasi, UGC-FIP fellowship to D. Santhi Priya, UGC-JRF to B Swathi, CSIR - JRF to M. Ravi Kumar, TEQIP Fellowship to K. Jaya Rao.

\section{References}

1. Ley S V, Baxendale I R, Bream R N, Jackson P S, Leach A G, Longbottom D A, Nesi M, Scott J S, Storer R I and Taylor S J 2000 J. Chem. Soc. Perkin. Trans. 1233815 and references cited therein

2. Domling A 2006 Chem. Rev. 17106

3. Heeres J, Backx L J J, Mostmans J H and Van Custem J 1979 J. Med. Chem. 221003

4. Tanigawara Y, Aoyama N, Kita T, Shirakawa K, Komada F, Kasuga M and Okumura K 1999 Clin. Pharmacol. Ther. 66528

5. Brimblecombe R W, Duncan W A M, Durant G J, Cemmett J C, Ganellin C R and Parsons M E 1975 J. Int. Med. Res. 386

6. Dorneanu O, Popovici I, Boiculese L and Bosnea D J 2003 J. Prev. Med. 1141

7. Dinh H T, Kernabaum S and Frottier J 1978 Lancet 338 3111

8. Lee J, Laydon J, McDonnell P, Gallagher T, Kumar S, Green D, McNulty D, Blumenthal N, Heys J, Landvatter S, Strickler J, Mclaughlin M, Siemens I, Fisher S, Livi J, White J, Adams J and Young P 1994 Nature 372739

9. Heeres J, Backx L, Mostmans J and Vancustem J 1979 J. Med. Chem. 221003

10. Baures P W 1991Org. Lett. 2249 
11. Sarshar S, Siev D and Mjalli M M 1996 Tetrahedron Lett. 37835

12. Shaabani A and Rahmati A 2006 J. Mol. Catal. A Chem. 246249

13. Sharma S D, Hazarika P and Konwar D 2008 Tetrahedron Lett. 492216

14. Sangshetti J N, Kokare N D, Kotharkara S A and Shinde D B 2008 J. Chem. Sci. 120463

15. Kidwai M, Mothsra P, Bansal V, Rishi K S, Abdul S E, Sharmistha D and Tej P S 2007 J. Mol. Catal. A: Chem. 265177

16. Seyedeh F H, Seyede A N and Zahra B 2012 Monatsh. Chem. 144387

17. Heravi M M, Bekhtiari K, Oskooie $\mathrm{H}$ A and Taheri S 2007 J. Mol. Catal. A Chem. 263279

18. Siddiqui S A, NarkhedeU C, Palimkar S S, Daniel T, Loholi R J and Srinivasan K V 2005 Tetrahedron 61 3539

19. Balalaie S, Arabanian A and Hashtroudi M 2008 Monatsh. Chem. 139125

20. Sharma G, Jyothi Y and Lakshmi P 2006 Syn. Comm. 362991
21. Kooti M and Afshari M 2012 Catal. Lett. 142319

22. Murthy Y L N, Diwakar B S, Govind B, Nagalakshmi K, Kasiviswanath I V and Rajendra singh 2012 J. Chem. Sci.124 639

23. Kantam M L, Yadav J, Soumi L, Srinivas P, Sreedhar B and Figueras F 2009 J. Org. Chem. 744611

24. Shin H-C, Choi S-C, Jung K-D and Han S-H 2001Chem. Mater. 2001131238

25. Panda N, Jena A K, Mohapatra S and Rout S R 2011 Tetrahedron Lett. 521924

26. Polshettiwar V, Baruwati B and Varma R S 2009 Green Chem. 11127

27. Nasir Baig R B and Varma R S 2013 Chem. Commun. 49752

28. Scherrer P 1918 Mathematisch-Physikalische Klasse 2 98

29. Langford J and Wilson A 1978 J. App. Cryst. 11 102

30. Jenkins R and Snyder R L 1996 In X-ray powder Diffractometry: An introduction (New York: John Wiley) 89

31. Javad S and Zohre Z 2012 Iranian J. Catal. 2(3) 121 